\begin{tabular}{|c|c|c|}
\hline & International Journal of Current Research in & \\
\hline & Biosciences and Plant Biology & \\
\hline PUBLI & $\begin{array}{c}\text { ISSN: 2349-8080 (Online) } \bullet \text { Volume } 3 \bullet \text { Number } 4 \\
\text { Journal homepage: www.ijcrbp.com }\end{array}$ & \\
\hline
\end{tabular}

\title{
Evaluation of In Vitro Radical Scavenging and Antihemolytic Efficacy of a Polyherbal Combination Prepared from Traditional Blood Purifiers
}

\author{
Ananda Vardhan Hebbani*, Mythreyi S. Jamadagni, M. Chaitra, Kruthi R Purnachandra, \\ Aviral Singh, P. Jyothy and V. Pragathi
}

Department of Biotechnology, New Horizon College of Engineering, Bengaluru, Karnataka-560 103, India

*Corresponding author.

\section{Abstract}

The present work is an attempt to look at the possible synergistic role the chosen phytoextracts would contribute in making an effective herbal combination with enhanced anti-oxidant potential. Aqueous extracts of Achyranthes aspera, Amaranthus caudatus, Calotropis procera, Gymnema sylvestre and Taraxacum officinale were examined for their individual phytoconstituent profile and a polyherbal combination was prepared which showed an encouraging result in terms of the radical scavenging and anti-haemolytic activities.

\section{Article Info}

Accepted: 20 March 2016

Available Online: 06 April 2016

\section{Ke y w ords}

Aqueous extracts

Anti-hemolytic

Polyherbal formulations

Radical scavenging

\section{Introduction}

Traditional / Ayurvedic system is an indigenous medicational practice and knowledge of using plants / herbal derivatives for the maintenance of health [Ayuh life, Veda-knowledge]. Ayurvedic approach towards the treatment of diseases has become popular due to the fact that it has no side effects as compared to other. Polyherbalism has been dated centuries ago in the Ayurvedic literature "Sarangdhara Samhita" (Murthy, 2006).

Typically, a polyherbal preparation is a combination of many herbal extracts used to give a therapeutic effect wherein the multiple constituents contributed by the individual phytoextracts, appropriately complement each other and become an effective medicational alternative with an enhanced therapeutic potential (Tiwari and Rao, 2002). Even though the active phytochemical constituents of individual plants have been well established, they usually are present in minute amounts and are always insufficient to achieve the desired therapeutic effects (Gupta et al., 2010). For this, scientific studies have revealed that these plants of varying potencies when combined may theoretically produce a greater result, as compared to the individual use of the plant and also the sum of their individual effects. This phenomenon of positive herb-herb interaction is known as synergism and moreover certain pharmacological actions of active constituents of herbals are significant only when potentiated by that of other plants, but not evident when used alone (Lau et al., 2012)

To look at the effectiveness of synergism in treating a specific condition, a polyherbal combination was prepared using the traditionally mentioned blood purifiers and its efficiency in ameliorating the free radical induced damage of human erythrocytes (Khare, 2008). The sedentary lifestyles patterns viz., smoking, chronic alcohol consumption and exposure to harmful chemicals etc. have been understood to be the key factors resulting in causing many pathophysiological changes to 
all the major body parts, mainly due to the excess deposition of free radicals (Laufs et al., 2005; Radak et al., 2008). Blood being the major fluid connective tissue acts as a mediator for transportation of these free radicals and thus will be easily prone for the free radical induced pathogenesis (Halliwell and John, 2015; Hebbani et al., 2014). Free radical induced damage on blood is better understood by taking RBC as a simple membrane modal, which are known to undergo many biochemical changes due to the excess free radicals resulting in their reduced life span (Sies, 2013). Since the individual constituents used in preparing the polyherbal preparation are traditionally mentioned as blood purifiers, we aimed at making a polyherbal combination that can efficiently scavenge the free radicals and protect the RBC's there by acting as an efficient blood purifier. Here we aim at looking into the therapeutic potentials of five well-documented medicinal plants Achyranthes aspera, Amaranthus caudatus, Calotropois procera, Gymnema sylvestre and Taraxacum officinale which are frequently mentioned in used the traditional medicinal literature as blood purifiers (Khare, 2008); but without any scientific proof of evidence. The present work is thus an attempt to forward some parameters which can be used as criteria for scientifically categorising the traditionally used blood purifiers.

Achyranthes aspera is an erect or procumbent, annual or perennial herb growing upto 1-2 meter of height. Traditionally, the plant is used to treat asthma and cough. It is pungent, antiphlegmatic, antiperiodic, diuretic, purgative and laxative, useful in oedema, dropsy, piles, boils and eruptions of skin (Srivastav et al., 2011; Goyal et al., 2007). Inhaling the fume of Achyranthes aspera mixed with Smilax ovalifolia roots is suggested to improve appetite and to cure various types of gastric disorders (Bhattaraj, 1992). A fresh piece of root is used as tooth brush. Paste of the roots in water is used in ophthalmia and opacities of the cornea. Paste of fresh leaves is used for allaying pain from bite of wasps (Gupta, 2010). The plant is useful in liver complaints, rheumatism, scabies and other skin diseases. It also possesses tranquillizing properties and the whole plants contain alkaloids achyranthin and betaine which is known to dilate blood vessels (Khare, 2008).

Amaranthus caudatus acts as a blood-purifier and a diuretic, used in treating piles, strangury and dropsy. Antimicrobial peptides have been isolated from its seeds and in Western herbal medicine Amaranthus caudatus is used for ulcers, diarrhoea, as well as inflammation of the mouth and throat. Preliminary evidences suggests that
Amaranth seed can reduce total cholesterol and LDL, while increasing HDL (Khare, 2008; Plate and Jose, 2002; Kumar et al., 2010).

Calotropois procera is a widely distributed plant with all the parts, viz, root, stem, leaf and flowers having medicinal value according to the indigenous system of medicine (Samvatsar and Diwanji, 2000). The plant is used against bronchial asthma, dyspepsia, flatulence, constipation and mucus in stool (Khare, 2008). Compounds derived from the plant have been found to have emeto-cathartic and digitalic properties and the principal active medicinals are asclepin and mudarin (Rasik et al., 1999). Other compounds have been found to have bactericidal and vermicidal properties and the latex was found to contain a proteolytic enzyme called calotropaine (Begum et al., 2013). An infusion of bark powder is used in the treatment and cure of leprosy and elephantiasis and is advisable to use bark that has been kept for more than a year (Kumar and Basu, 1994). The plant is identified to contain benzoylline- olone, benzolisolineolone, beta-amyrin, and vanidin. It also contains cardenolide, proceragenin, an antibacterial principle (Khare, 2008).

Gymnema sylvestre is an indigenous herb, belonging to the class dicotyledonous of the family Asclepiadaceae. The plant is a good source of a large number of bioactive substances (Saneja et al., 2010; Manohar et al., 2009). It is one of the major botanicals used in Ayurvedic system of medicine to treat conditions ranging from diabetes, malaria, to snakebites (Leach, 2007). Although the herb is widely used as a naturopathic treatment for diabetes it also demonstrates promising effects in the treatment of obesity, arthritis, hyperlipidemia, Parkinsonism, and hypercholesterolemia (Malik et al., 2010). Furthermore, the bioactive compounds of plant have antimicrobial, blood purifying, anti-inflammatory and anticancer properties. It contains Gymnemagenin, the main sapogenin in the leaves (Khare, 2008).

Taraxacum officinale, known as dandelion, has been used in folk medicine in the treatment of hepatic disorders, inflammation and several women's diseases such as breast and uterus cancers (Sweeney et al., 2005; Schutz et al., 2005). In Traditional Chinese medicine, it is also acclaimed as a nontoxic herb with exceptional values for its choleretic, diuretic, anti-rheumatic and antiinflammatory properties (Jeon et al., 2008). Several flavonoids including caffeic acid, chlorogenic acid, luteolin, and luteolin 7-glucoside have been isolated from the dandelion (Williams et al., 1996). 


\section{Materials and methods}

\section{Plant material}

Shade dried leaves of Achyranthes aspera, whole plant of Amaranthus caudatus, roots of Calotropois procera, stem/leaves of Gymnema sylvestre and roots of Taraxacum officinale were procured from a local ayurvedic dealer and authenticated at National Ayurveda Dietetics Research Institute, Jayanagar, Bangalore and voucher specimens were deposited in the institutes herbarium.

\section{Chemicals}

Standard polyphenols: gallic acid, tannic acid, catechin, $\beta$ sitosterol, rutin, quercetin and betain were of HPLC grade with $99 \%$ purity. 2,2-diphenyl-1-picrylhydrazyl $[\mathrm{DPPH}]$, hydrogen peroxide and butylatedhydroxy anisole [BHA] were procured from Sigma Chemicals. All the other chemicals were of analytical grade.

\section{Extract preparation}

Aqueous extracts of Achyranthes aspera [AAA], Amaranthus caudatus [AAC], Calotropis procera [ACP], Gymnema sylvestre [AGS] and Taraxacum officinale [ATO] were prepared by using sequential extraction method (Hebbani et al., 2015)

\section{Preparation of polyherbal combination}

Polyherbal combination [PHC] was prepared by mixing the grams equivalent to a measured concentration of GAE as mentioned in Table 2.

\section{Total phenolic, flavonoid and tannin contents}

Total phenolic content [TPC] expressed as milligrams of gallic acid equivalents [GAE] per gram of dry extract [mg GAE/g of dry extract]; Total flavonoid content [TFC] expressed as milligrams of rutin equivalents [RE] per gram of dry extract [mg RE/g of dry extract] and the Total Tannin content [TC] of both the individual phytoextracts and the PHC were determined using the standard methods as mentioned earlier (Hebbani et al., 2014).

\section{Identification and quantification of polyphenols using HPLC}

Polyphenolic profiles of all the extracts were determined by chromatographically separating them on a reverse phase Luna $5 \mu \mathrm{m}$ C18 [2] [100 ̊, LC Column 250 x 4.6 $\mathrm{mm}$ ]. A solvent mixture of Methanol / Phosphate buffer [pH 3] taken in the ratio of 70:30 was used as a mobile phase and with a flow rate of $1 \mathrm{ml} / \mathrm{min}$ the isocratic elution of hydrophobic polyphenols was achieved. Quantification of the polyphenols individually in of the extracts was achieved by comparing the chromatogram with that of standards $[100 \mu \mathrm{g} / \mathrm{ml}]$ such as gallic acid, tannic acid, catechin, $\beta$ sitosterol, rutin, quercetin and betain.

\section{In vitro radical scavenging activity}

Hydrogen peroxide (Ak and Gulcin, 2008), Nitric oxide (Royer et al., 2011) and DPPH (Miliauskas et al., 2004) radical scavenging activities of the PHC were performed as mentioned elsewhere.

\section{Total reductive ability}

The total reductive ability of the PHC was colorimetrically evaluated according to the method described by Fu et al. (2010).

\section{Preparation of erythrocyte suspension}

Blood samples from healthy male / female [non-smoker and non-alcoholic] volunteers were collected into heparinised vaccuettes through venepuncture after taking informed consent. After gently swirling, the tubes were centrifuged at $1500 \mathrm{~g}$ for $10 \mathrm{~min}$ at $4^{\circ} \mathrm{C}$ and the plasma and buffy coat were removed. The resulting erythrocytes were washed thrice with 10 volumes of phosphate buffered saline [PBS $-10 \mathrm{mM}$ having $\mathrm{NaCl}-150 \mathrm{mM}$, $\mathrm{NaH}_{2} \mathrm{PO}_{4}-1.9 \mathrm{mM}$ and $\mathrm{Na}_{2} \mathrm{HPO}_{4}-8.1 \mathrm{mM}, \mathrm{pH}$ 7.4] and centrifuged at $1500 \mathrm{~g}$ for $5 \mathrm{~min}$. The buffy coat was carefully removed after each centrifugation and the erythrocyte suspension stock of $10 \% \mathrm{v} / \mathrm{v}$ was prepared in PBS, stored at $4^{0} \mathrm{C}$ and used within $6 \mathrm{hrs}$.

\section{In vitro hemolysis assay}

To look at the protective effect of PHC on the free radical induced oxidative damage on human erythrocytes, in vitro hemolysis assay was performed as

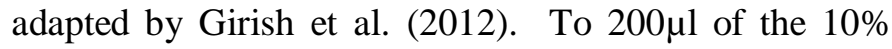
[v/v] RBC suspension, $50 \mu \mathrm{l}$ of PHC [5-25 $\mu \mathrm{g}$ GAE prepared in PBS] and $100 \mu \mathrm{l}$ of $\mathrm{H}_{2} \mathrm{O}_{2}[200 \mu \mathrm{M}$ prepared in PBS, pH7.4] were added and the reaction mixture was incubated at $37^{\circ} \mathrm{C}$ for $30 \mathrm{~min}$ and centrifuged at $2000 \mathrm{~g}$ for $10 \mathrm{~min}$. To $200 \mu 1$ of the supernatant, $800 \mu 1$ of PBS was added and the absorbance was monitored at $410 \mathrm{~nm}$. 
Control was prepared by incubating erythrocyte suspension directly with $\mathrm{H}_{2} \mathrm{O}_{2}$ to obtain complete hemolysis and absorbance of supernatant was measured as mentioned. Sample controls were run at every individual concentration of the plant extract by incubating the erythrocyte suspension with plant extract. BHA was used as a standard antioxidant and the percentage of hemolysis was calculated by taking hemolysis caused by $200 \mu \mathrm{M} \mathrm{H}_{2} \mathrm{O}_{2}$ as $100 \%$.

\section{Statistical analysis}

All the experiments were done in triplicates and the data expressed as mean \pm SD and were analysed using XLSTAT software [Addinsoft Version 2013.4.04] and $p<0.05$ was considered to be statistically significant.

\section{Results and discussion}

\section{Total phenolic, flavonoid and tannin contents}

Plants are the known sources of multiple principles viz., phenolic acids, flavonoids, steroids, tannins, etc. which confer them with many therapeutic values (Bone and Simon, 2013). The concentrations of these polyphenols vary depending on many environmental factors and the extraction procedures employed (Björkman et al., 2011). The PHC aqueous extracts in the present study also were found to be very rich in their polyphenolic profile as presented in Table 1.

Table 1. Polyphenols in the polyherbal combination.

\begin{tabular}{llll}
\hline Extract & $\begin{array}{l}\text { Total phenolic content } \\
{[\mathbf{m g ~ G A E} / \mathbf{g}]}\end{array}$ & $\begin{array}{l}\text { Total flavonoid content } \\
{[\mathbf{m g ~ R E} / \mathbf{g}]}\end{array}$ & $\begin{array}{l}\text { Total tannic acid content } \\
{[\mathbf{m g} / \mathbf{g}]}\end{array}$ \\
\hline PHC & $34.02 \pm 3.08$ & $36.33 \pm 2.81$ & $20.00 \pm 1.01$ \\
AAA & $9.07 \pm 0.96$ & $25.01 \pm 2.12$ & $12.02 \pm 2.35$ \\
AAC & $10.42 \pm 1.01$ & $21.12 \pm 1.98$ & $13.01 \pm 1.95$ \\
ACP & $12.11 \pm 1.20$ & $17.80 \pm 1.36$ & $23.50 \pm 2.25$ \\
AGS & $29.19 \pm 3.28$ & $28.12 \pm 4.12$ & $9.84 \pm 1.02$ \\
ATO & $21.02 \pm 1.23$ & $17.35 \pm 2.24$ & $15.09 \pm 2.02$ \\
\hline
\end{tabular}

Mean \pm SD of three sample replicates $\mathrm{n}=3, p<0.05$.

The net concentrations of phenolics, flavonoids and tannins was observed to be not just a mere average of all the individual plant extracts, but was found to be varying, sometimes slightly lesser than the individual phytoextracts.

\section{Polyherbal combination}

Amount of the individual phytoextracts to be taken to prepare the PHC was determined based upon the concentrations of GAE in a fixed amount of individual phytoextracts which is represented in Table 2 .

Table 2. Amount of individual phytoconstituents added to prepare a polyherbal combination.

\begin{tabular}{lll}
\hline Samples & $\begin{array}{l}\text { Amount of GAE } \\
{[\mathbf{m g} \text { in } \mathbf{~} \mathbf{g} \text { of }} \\
\text { extract }\end{array}$ & $\begin{array}{l}\text { Wt. of sample taken } \\
\text { [g equivalent to 200 } \boldsymbol{\mu g} \\
\text { of GAE] }\end{array}$ \\
\hline AAA & 9.07 & 0.022 \\
AAC & 10.42 & 0.02 \\
ACP & 12.11 & 0.016 \\
AGS & 29.19 & 0.0068 \\
ATO & 21.02 & 0.0095 \\
\hline
\end{tabular}

\section{Quantification of polyphenols using HPLC}

The individual polyphenols present in the PHC was further characterised using HPLC with columns specific for separating the hydrophobic compounds and UV detection at 280nm [Fig. 1].

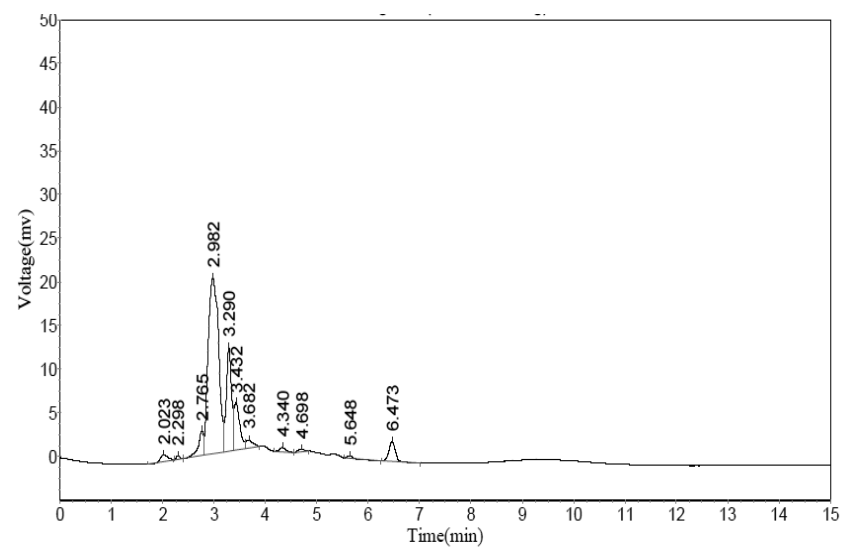

Fig. 1: HPLC Chromatogram for phenolic and flavonoid profile of the polyherbal combination.

The PHC had very high concentrations of flavonoids [catechin > rutin > quercetin] together accounting for almost $80 \%$ of the total polyphenolic profile; followed by 
moderate concentrations of phenolic acids [tannic acid > Gallic acid] [Table 3]. Steroidal content was found to be minimal is the PHC [ $\beta$ sitosterol $-5 \%$ ].

Table 3. Concentrations of the different polyphenols quantified in polyherbal combination [Calculated by taking standards peak areas into consideration].

\begin{tabular}{lll}
\hline Polyphenol & $\begin{array}{l}\text { Ret. time } \\
\text { [min] }\end{array}$ & $\begin{array}{l}\text { Concentration } \\
\text { [ } \boldsymbol{\mu g} / \mathbf{g} \text { of extract] }\end{array}$ \\
\hline$\beta$ sitosterol & 2.298 & $8.9 \pm 0.7$ \\
Gallic acid & 2.765 & $14.12 \pm 1.74$ \\
Catechin & 2.982 & $358 \pm 8.12$ \\
Rutin & 3.290 & $258 \pm 5.23$ \\
Tannic acid & 3.432 & $101 \pm 3.20$ \\
Quercetin & 6.473 & $31 \pm 1.02$ \\
\hline
\end{tabular}

\section{In vitro radical scavenging activity}

Free radical is a species that contains one or more unpaired electrons with a capability of independent existence. Free radicals such as trichloromethyl, superoxide, hydroxyl, peroxyl and nitric oxide are known to be produced metabolically in living organisms. In addition, some non-radical derivatives of oxygen molecules [hydrogen peroxide, hypochlorous acid], can be generated in foods and biological systems. All of this reactive oxygen can cause deleterious effects to the general functioning of the system and thus the tests of the ability of a substance to scavenge radical species may be relevant in the evaluation of antioxidant activity (Sanchez, 2002).

To look at the antioxidant potential of aqueous extracts of the plants, in vitro radical scavenging activities were performed which showed an enhanced radical scavenging ability of the PHC in comparison to the individual phytoextracts. Results of the $\mathrm{EC}_{50}$ values for both the plants for the different antioxidant assays are presented in Table 4.

Table 4. $\mathrm{EC}_{50}$ values of PHC for hydrogen peroxide, nitric oxide and DPPH radical scavenging assays in comparison with the respective standard antioxidants.

\begin{tabular}{llll}
\hline Radical Scavenging assay & PHC & Ascorbic acid & BHA \\
\hline Hydrogen peroxide $[\mu \mathrm{g} / \mathrm{ml}]$ & $39.21 \pm 0.04$ & - & $30.08 \pm 0.05$ \\
Nitric oxide $[\mathrm{mg} / \mathrm{ml}]$ & $0.421 \pm 0.05$ & $0.364 \pm 0.07$ & - \\
DPPH free radical $[\mathrm{mg} / \mathrm{ml}]$ & $8.58 \pm 0.01$ & $4.04 \pm 0.08$ & - \\
\hline
\end{tabular}

As seen in Fig. 2A, there is a concentration dependent rise in the hydrogen peroxide radical scavenging ability of the PHC with the $\mathrm{EC}_{50}$ value, higher than that of standard antioxidant- BHA. Fig. 2B depicts NO scavenging activity of the PHC which is also higher in comparison to that of the standard antioxidant viz., ascorbic acid. PHC showed a concentration dependent rise in the \% of inhibition of DPPH free radical as shown in Fig. 2C; with $\mathrm{PHC}$ having a greater efficacy to scavenge the free radicals compared to the standard antioxidant (Table 4).

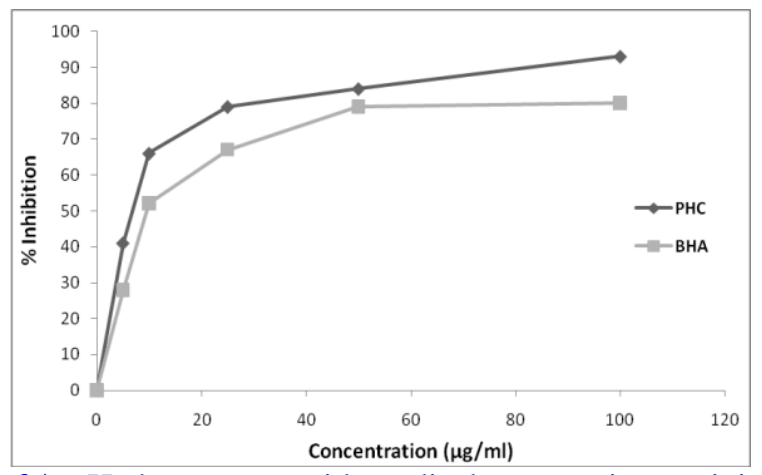

Fig. 2A: Hydrogen peroxide radical scavenging activity of polyherbal combination. Values are mean \pm SD of three sample replicates, $\mathrm{n}=3, p<0.05$.

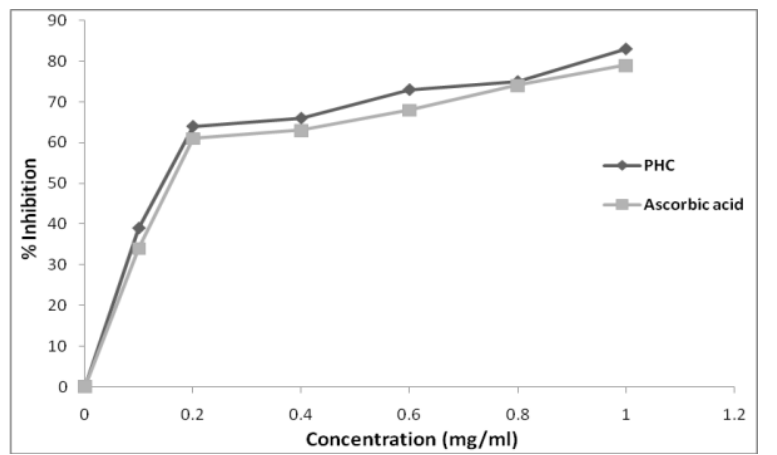

Fig. 2B: Nitric oxide radical scavenging activity of polyherbal combination. Values are mean \pm SD of three sample replicates, $\mathrm{n}=3, p<0.05$.

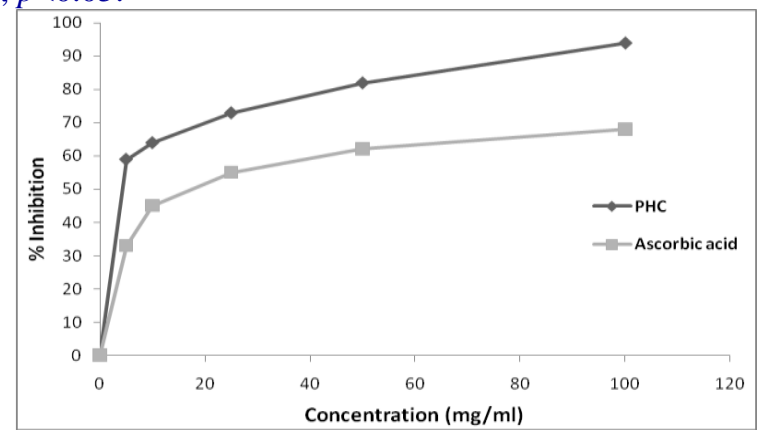

Fig. 2C: DPPH radical scavenging activity of polyherbal combination. Values are mean $\pm \mathrm{SD}$ of three sample replicates, $\mathrm{n}=3, p<0.05$. 


\section{Total reductive ability}

HC was assessed for its overall reductive ability which accounts for their general antioxidant and therapeutic potentials rendered by the individual phytoprinciples from the different extracts. Fig. 3 represents the trend of increase in absorbance with the increase in concentration of the PHC. At a very low concentration of $0.10 \mathrm{mg} / \mathrm{ml}$ PHC reached an absorbance value of $>1$, suggesting its potential therapeutic ability.

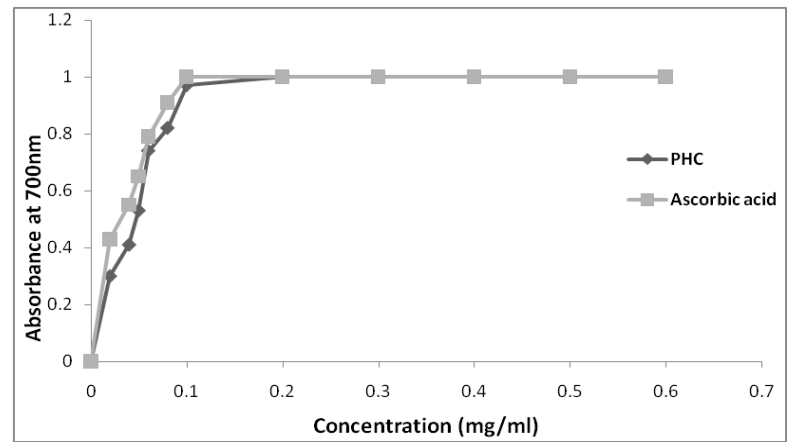

Fig. 3: Reductive ability of polyherbal combination. Values are mean $\pm \mathrm{SD}$ of three sample replicates, $\mathrm{n}=3, p<0.05$

\section{In vitro antihemolytic assay}

Erythrocytes present a good model for analysis of membrane stability based on their resistance to lysis in response to variation in solvent tonicity and thus have been widely used for the study of oxidative stress. Rupture of RBC membrane releases haemoglobin which can be measured spectrophotometrically (De Freitas et al., 2010). In this work, oxidative damage of erythrocytes was induced by using $\mathrm{H}_{2} \mathrm{O}_{2}$ and the protective effect of the PHC against the free radical induced oxidative damage was assessed. Dose dependent increase in the percentage inhibition of hemolysis was observed with $\mathrm{ED}_{50}$ value of $14.21 \mu \mathrm{g} \mathrm{GAE}$, lesser than that of standard antioxidant- BHA [17.16 $\mu \mathrm{g}$ GAE] which is a significant observation (Fig. 4).

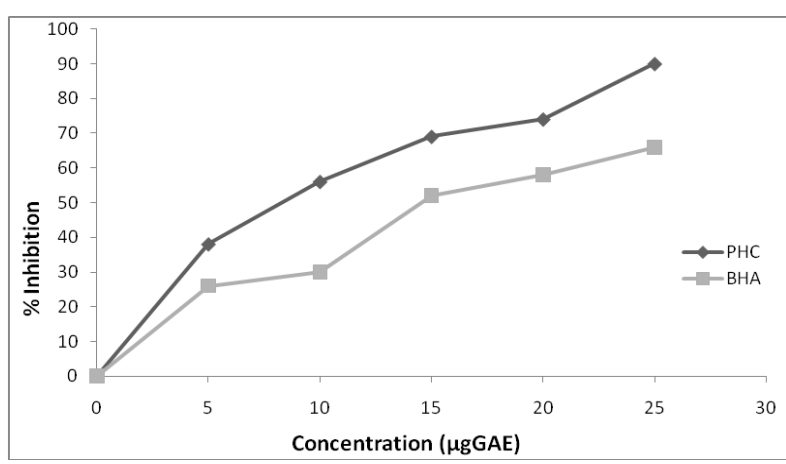

Fig. 4: In vitro antihemolysis assay of polyherbal combination. Values are mean $\pm \mathrm{SD}$ of three sample replicates, $\mathrm{n}=6, p<0.05$.

\section{Conclusions}

Effect of different xenobiotic compounds and the subsequent reactive intermediary metabolites on the biochemical process of the system are always intervening which cause tremendous impedance on the system due to the oxidative stress (Valavanidis et al., 2006). In addition to the health and nutritional status of an individual, the inherent antioxidant capacity that the individual possess do play a critical role in deciding the extent of damage the xenobiotic compound would cause on the system.

Blood being the major connective tissue of the body, is most prone for the free radicals [superoxide, hydroxyl, nitric oxide, hydrogen peroxide, hypochlorous acid and peroxynitrite] induced damage, resulting in a shortened red cell life span as observed during many haemolytic disorders, enzyme deficiencies and abnormalities of membrane structure or haemoglobin synthesis (Halliwell and John, 2015; Pryor, 2012).

An imbalance in the proportions of free radicals generated and the inherent antioxidant repertoire of the system has been demonstrated to account for shortened life span of normal red cells in various diseases. Other than this, diseased conditions like diabetes, infections and hypoxia may also cause increased oxidative stress and red cell damage by free radical generation. Infections and hypoxia seem to be particularly responsible for reduced red cell life span in the premature infants in whom the antioxidant system is usually inefficient (Buonocore et al., 1999).

Flavonoids and polyphenolic compounds richly seen in foods of plant origin are known to have various therapeutic effects and have been shown to protect biological membranes against free radical-induced oxidative damage. All the chosen members of the PHF combination in the present study are traditionally used as blood purifiers and but the independent efficacies has not been tested. The present work gives an encouraging indication of a synergistic action conferred by the independent phytoextracts and the positive drug-drug interactions with the protective action conferred because of the complementing action of the individual phytochemicals from the different phytoextracts.

\section{Conflict of interest statement}

Authors declare that they have no conflict of interest. 


\section{References}

Ak, T. and Gülçin, İ., 2008. Antioxidant and radical scavenging properties of curcumin. Chemico-biol. Interact. 174(1), 27-37.

Begum, N., Sharma, B. and Pandey, R.S., 2013. Calotropis procera and Annona squamosa: potential alternatives to chemical pesticides. British J. Appl. Sci. Technol. 3(2), 254.

Bhattaraj, N.K., 1992. Folk use of plants in veterinary medicine in Central Nepal. Fitoter. 63, 497-506.

Björkman, M., Klingen, I., Birch, A.N., Bones, A.M., Bruce, T.J., Johansen, T.J., Meadow, R., Mølmann, J., Seljåsen, R., Smart, L.E. and Stewart, D., 2011. Phytochemicals of Brassicaceae in plant protection and human healthInfluences of climate, environment and agronomic practice. Phytochem. 72(7), 538-556.

Bone, K. and Mills, S., 2013. Principles and Practice of Phytotherapy: Modern Herbal Medicine. Elsevier Health Sciences.

Buonocore, G., Perrone, S., Gioiaa, D., Gatti, M.G., Massafra, C., Agosta, R. and Bracci, R., 1999. Nucleated red blood cell count at birth as an index of perinatal brain damage. Amer. J. Obstet. Gynecol. 181(6), 1500-1505.

De Freitas, M.V., De Oliveira, M.R., Dos Santos, D.F., Netto, R.D.C.M., Fenelon, S.B. and Penha-Silva, N., 2010. Influence of the use of statin on the stability of erythrocyte membranes in multiple sclerosis. J. Membr. Biol. 233(13), 127-134.

Fu, W., Chen, J., Cai, Y., Lei, Y., Chen, L., Pei, L., Zhou, D., Liang, X. and Ruan, J., 2010. Antioxidant, free radical scavenging, anti-inflammatory and hepatoprotective potential of the extract from Parathelypteris nipponica (Franch. et Sav.) Ching. J. Ethnopharmacol. 130(3), 521528.

Girish, T.K., Vasudevaraju, P. and Rao, U.J.P., 2012. Protection of DNA and erythrocytes from free radical induced oxidative damage by black gram (Vigna mungo L.) husk extract. Food Chem. Toxicol. 50(5), 1690-1696.

Goyal, B.R., Goyal, R.K., Mehta, A.A., 2007. Phytopharmacology of Achyranthes aspera: A review. Pharmacog. Rev. 1(1), 143.

Gupta, R.K., 2010. Medicinal and Aromatic Plants. CBS Publishers and Distributors, 234. p.499.

Gupta, Y.K., Briyal, Seema and Gulati, Anil., 2010. Therapeutic potential of herbal drugs in cerebral ischemia. Ind. J. Physiol. Pharmacol. 54(2), 99-122.

Halliwell, B. and Gutteridge, J.M., 2015. Free radicals in biology and medicine. Oxford University Press, USA.

Hebbani, A.V. and Varadacharyulu, N.C., 2015. Protective Effect of aqueous bark extract of Terminalia Arjuna against Alcohol-Induced Hepato and Nephrotoxicity in Rats. Int. J. Phytomed. 7(2), 142-153.

Hebbani, A.V., Reddy, V.D. and Nallanchakravarthula, V., 2014. In Vitro Anti-hemolytic Activity of Terminalia arjuna (Roxb.) Wt. \& Arn. Bark Powder Aqueous Extract. Ind. J. Adv. Chem. Sci. 3, 02-108.
Jeon, H.J., Kang, H.J., Jung, H.J., Kang, Y.S., Lim, C.J., Kim, Y.M. and Park, E.H., 2008. Anti-inflammatory activity of Taraxacum officinale. J. Ethnopharmacol. 115(1), 82-88.

Khare, C.P., 2008. Indian Medicinal Plants: An Illustrated Dictionary. Springer Science \& Business Media.

Kumar, A., Lakshman, K., Jayaveera, K.N., Nandeesh, R., Manoj, B. and Ranganayakulu, D., 2010. Comparative in vitro anthelmintic activity of three plants from the Amaranthaceae family. Arch. Biol. Sci. 62(1), 185-189.

Kumar, V.L., Basu, N., 1994. Anti-inflammatory activity of the latex of Calotropis procera. J. Ethnopharmacol. 44(2), $123-125$.

Lau, K.M., Lai, K.K., Liu, C.L., Tam, J.C.W., To, M.H., Kwok, H.F., Lau, C.P., Ko, C.H., Leung, P.C., Fung, K.P. and Poon, S.K.S., 2012. Synergistic interaction between Astragali Radix and Rehmanniae Radix in a Chinese herbal formula to promote diabetic wound healing. J. Ethnopharmacol. 141(1), 250-256.

Laufs, U., Wassmann, S., Czech, T., Münzel, T., Eisenhauer, M., Böhm, M. and Nickenig, G., 2005. Physical inactivity increases oxidative stress, endothelial dysfunction, and atherosclerosis. Artheroscl. Thromb. Vascular Biol. 25(4), 809-814.

Leach, M.J., 2007. Gymnema sylvestre for diabetes mellitus: a systematic review. J. Alt. Compl. Med. 13(9), 977-983.

Malik, J.K., Manvi, F.V., Nanjware, B.R., Dwivedi, D.K., Purohit, P. and Chouhan, S., 2010. Anti-arthritic activity of leaves of Gymnema sylvestre R. Br. leaves in rats. Der Pharm. Lett. 2(1), 336-341.

Manohar, S.H., Naik, P.M., Praveen, N. and Murthy, H.N., 2009. Distribution of gymnemic acid in various organs of Gymnema sylvestre. J. For. Res. 20(3), 268-270.

Miliauskas, G., Venskutonis, P.R. and Van Beek, T.A., 2004. Screening of radical scavenging activity of some medicinal and aromatic plant extracts. Food Chem. 85(2), 231-237.

Murthy, K.R.S., 2006. Sarangadhara Samhita. Varanasi: Chaukamba orientalia, p.255.

Plate, A.Y. and Arêas, J.A., 2002. Cholesterol-lowering effect of extruded amaranth (Amaranthus caudatus L.) in hypercholesterolemic rabbits. Food Chem. 76(1), 1-6.

Pryor, W. (Ed.), 2012. Free Radicals in Biology (Vol. 6). Elsevier.

Radak, Z., Chung, H.Y. and Goto, S., 2008. Systemic adaptation to oxidative challenge induced by regular exercise. Free Rad. Biol. Med. 44(2), 153-159.

Rasik, A.M., Raghubir, R., Gupta, A., Shukla, A., Dubey, M.P., Srivastava, S., Jain, H.K. and Kulshrestha, D.K., 1999. Healing potential of Calotropis procera on dermal wounds in Guinea pigs. J. Ethnopharmacol. 68(1), 261266.

Royer, M., Diouf, P.N. and Stevanovic, T., 2011. Polyphenol contents and radical scavenging capacities of red maple (Acer rubrum L.) extracts. Food Chem. Toxicol. 49(9), 2180-2188.

Samvatsar, S., Diwanji, V.B., 2000. Plant sources for the treatment of jaundice in the tribals of Western Madhya Pradesh of India. J. Ethnopharmacol. 73(1), 313-316. 
Sánchez-Moreno, C., 2002. Review: Methods used to evaluate the free radical scavenging activity in foods and biological systems. Food Sci. Technol. Int. 8(3), 121-137.

Saneja, A., Sharma, C., Aneja, K.R. and Pahwa, R., 2010. Gymnema sylvestre (Gurmar): a review. Der Pharm. Lett. 2(1), 275-284.

Schütz, K., Carle, R. and Schieber, A., 2006. Taraxacum-a review on its phytochemical and pharmacological profile. J. Ethnopharmacol. 107(3), pp.313-323.

Sies, H. ed., 2013. Oxidative stress. Elsevier.

Srivastav, S., Singh, P., Mishra, G., Jha, K.K. and Khosa, R.L., 2011. Achyranthes aspera-An important medicinal plant: A review. J. Nat. Prod. Plant Resour. 1(1), 1-14.

Sweeney, B., Vora, M., Ulbricht, C. and Basch, E., 2005. Evidence-based systematic review of dandelion
(Taraxacum officinale) by natural standard research collaboration. J. Herbal Pharmacother. 5(1), 79-93.

Tiwari, A.K. and Madhusudanarao, J., 2002. Diabetes mellitus and multiple therapeutic approaches of phytochemicals: Present status and future prospects. Curr. Sci. 83, 30-38.

Valavanidis, A., Vlahogianni, T., Dassenakis, M. and Scoullos, M., 2006. Molecular biomarkers of oxidative stress in aquatic organisms in relation to toxic environmental pollutants. Ecotoxicol. Environ. Safety, 64(2), 178-189.

Williams, C.A., Goldstone, F., Greenham, J., 1996. Flavonoids, cinnamic acids and coumarins from the different tissues and medicinal preparations of Taraxacum officinale. Phytochem. 42(1), 121-127.

\section{How to cite this article:}

Hebbani, A.V., Jamadagni, M. S., Chaitra, M., Purnachandra, K. R., Singh, A., Jyothy, P., Pragathi, V., 2016. Evaluation of in vitro radical scavenging and antihemolytic efficacy of a polyherbal combination prepared from traditional blood purifiers. Int. J. Curr. Res. Biosci. Plant Biol. 3(4), 56-63. doi: http://dx.doi.org/10.20546/ijcrbp.2016.304.010 